\title{
O conceito de recepção na obra de Eliseo Verón: 1968 - 2013
}

Antônio Fausto Neto

Resumo: O conceito de recepção atravessa a obra de Eliseo Verón - 1968-2013. Estudos iniciais enfatizam a dimensão temporal para a produção de sentidos, destacando processos que envolvem momentos específicos para definição da significação: o instante em que uma mensagem é dita e aquele em que é recebida. Tal aspecto tem merecido pouca atenção, mas é algo que exigiria, segundo Verón, muito no futuro. O papel dos atores é destacado, pois reconstruir gramáticas de reconhecimento supõe trabalhar com a palavra individual. Descreve-se a pertinência da noção de "gramáticas" - suas incompletudes e diferentes lógicas - para a formulação da teoria do reconhecimento, a partir da articulação produção/recepção.

Palavras-chave: produção/recepção; reconhecimento; interpenetração.

Abstract: The concept of reception in Eliseo Verón's work: 1968 - 2013 - The concept of reception runs through the work of Eliseo Verón - 1968-2013. Initial studies emphasize the dimension of time for the production of meaning. They highlight processes that involve specific moments for the definition of the signification, in which a message is said and received. Little attention has been paid for this aspect, but it is an issue that would demand a lot in the future. The actors' role is pointed out, since rebuilding recognition grammars assumes the work with the individual word. The pertinence of the idea of "grammars" is developed - its deficiencies and different logics - for the formulation of theory of recognition, from the articulation production/reception.

Keywords: production/reception; recognition; interpenetration.

\section{Nota introdutória}

O conceito de recepção se elabora na obra sociossemiótica de Eliseo Verón ao longo de, pelo menos, cinco décadas. Uma hipótese o acompanha, ou resulta desta processualidade - a de que a comunicação, qualquer que seja o seu nível, realiza-se em torno de um desequilíbrio. Vincula-se ou resulta de observações sobre objetos, em diferentes momentos: nas primeiras entrevistas com pacientes mentais; na elaboração da noção de gramáticas; na análise dos discursos jornalísticos, políticos, etc.; no longo ciclo do trabalho de campo sobre a situação de recepção, pesquisas na França e na Argentina, 
entre anos 80 e 90; na criação de espaços de estudo (como o CISECO), já nos seus últimos anos de vida. Sua hipótese inaugural propõe que produção e recepção não são conjuntos idênticos, pois não há coincidência entre as condições de produção e de reconhecimento de um determinado conjunto significante (VERÓN, 1978). Afasta-se da concepção segundo a qual há um trabalho exitoso de transferência de signos, entre A e B (nomeados como emissor e receptor). E propõe que, tanto a comunicação interpessoal como a midiática, realizam-se em torno de um desajuste entre estes dois níveis, e que as intenções entre A e B não se efetivam de modo contínuo e em termos automáticos.

\section{Primeiras elaborações}

A hipótese acima apontada envolve as condições do trabalho que transforma signos em sentidos, chamando atenção para o fato de que todo processo de comunicação está atravessado por uma assimetria constitutiva, entre P/R (Produção/Recepção). Os sentidos se enunciariam a partir de uma dinâmica caracterizada mais por indeterminações do que convergências. Tal transformação não obedeceria a uma atividade consciencial e nem linear, conforme concebida pelo paradigma funcionalista. Gera-se o desequilíbrio como fonte de complexidade. Esta assimetria se manifestaria em qualquer nível de comunicação e se complexificaria sobretudo no contexto de práticas da comunicação midiática, pelo fato de que a presença de novas manifestações tecno-discursivas aumentariam a distância entre produção e recepção (VERÓN, 1986). Entretanto, alguns trabalhos empíricos do autor "confirmam a defasagem, esta descontinuidade entre análise em produção e análise em recepção, bem como a importância de esforços destinados para os articular" (VERÓN, 1985, p.102). A perspectiva da teoria da informação define esta passagem de $\mathrm{P} / \mathrm{R}$, como circulação, mas a concebe apenas como uma instância por onde se efetuaria transferência de signos de emissor/receptor. Verón, porém, vê esta instância dotada de um outro modo de existência, ou seja, como fonte de um trabalho. Acentua a importância do desequilíbrio (defasagem) entre $\mathrm{P} / \mathrm{R}$, como diferença da relação destes dois polos. Esta seria constitutiva de um modelo de circulação, no qual os signos são transformados em sentidos, ao passar por um trabalho de dois circuitos produtivos (P/R) que operam segundo lógicas e condições distintas, cujos efeitos não seriam conhecidos previamente e nem se efetivariam, unilateralmente. Ao lançar a hipótese segundo a qual a assimetria é um princípio válido em todos os níveis da comunicação, Verón acrescenta ainda que a defasagem entre $\mathrm{P} / \mathrm{R}$ reúne condição necessária para produção dos sentidos na medida em que estes se engendrariam no âmbito de feixes de relações discursivas produzidas no âmbito daqueles dois polos. Trabalha estas questões em seus primeiros estudos de análise de discursos, mas as re-enfatiza anos depois, ao reafirmar convicções, segundo as quais a produção de sentidos não se faz segundo lógicas de linearidades: 
Referi-me a esta diferença (entre $\mathrm{p} / \mathrm{r}$ ) no passado em termos de defasagem. Limitar-me-ei a recordar agora que é razoável postular que esta defasagem entre $\mathrm{p} / \mathrm{r}$ é uma propriedade constitutiva, estrutural de toda a comunicação em todos os níveis (mais ou menos microscópico ou macroscópico) de seu funcionamento, o que faz com que o esquema de comunicação seja assimétrico e irreversível (VERÓN, 2001, p.130).

A complexidade da defasagem entre $\mathrm{P} / \mathrm{R}$ aponta para um modo distinto de ver a recepção, tanto na modalidade comunicação mediática como no âmbito da comunicação face a face; mas em ambas, os contatos entre P/R não ocorrem sem mediação:

A comunicação humana é necessariamente 'mediada' em todos os seus níveis desde o micro até o macro, simplesmente porque o sentido só pode circular materializado; deste ponto de vista, a comunicação face a face - entre os indivíduos é tão 'mediada' como a circulação planetária de uma partida de futebol. A diferença crucial é que na transmissão da partida de futebol, a semiosis humana está mediatizada e a conversação não está. Nenhuma comunicação humana é 'direta' (por oposição a mediada) mas a midiatização produz, como veremos, importantes alterações de escala (VERÓN, 2013, p.148).

Tanto numa como noutra modalidade, os sentidos somente passam por regras e instruções específicas, nomeados como gramáticas, cujos efeitos, em vista da materialização de sentidos, não podem ser reconhecidos a priori:

[...] uma gramática de produção ou gramática de recepção tem a forma de conjuntos complexos de regras que descrevem operações [...] que permitem definir ora as condições de produção, ora os resultados de uma determinada leitura (VERÓN, 2006, p.51).

Mas as gramáticas são incompletas porque são submetidas a articulações múltiplas, que operam segundo lógicas distintas. Não podem assegurar efeitos de sentidos apenas a partir de suas próprias competências. Embora sejam também fontes de complexidades, não podem ser concebidas como pacotes que assegurem, unilateralmente, o êxito da performance discursiva. Se as gramáticas (P/R) estão em relação, não significa que estejam situadas em posição de convergência entre si. Já em 1978, no momento seminal do seu trabalho de análise de discurso, pontuava a complexidade da noção de desajuste e de acentuadas diferenças entre gramáticas:

[...] não se pode inferir de uma maneira direta e linear, [ os efeitos] das regras de reconhecimento (de um discurso), a partir da gramática de produção. Esta última define conjuntos de efeitos possíveis, mas a questão de saber qual concretamente a gramática de reconhecimento que foi aplicada a um texto em um momento dado, permanece inexplicável apenas pelas regras da produção (VERÓN, 1978a, p.11). 
Estas formulações representam reflexões seminais para o que viria a nomear como epistemologia da terceiridade, enquanto outros modos de olhar o funcionamento da recepção.

\section{Epistemologia da terceiridade}

Apoia-se em conceitos de interlocutores e em diagramas para descrever as formulações de seus achados, visando sistematizar suas hipóteses sobre o modelo de ternário de produção de sentido. Particularmente, as obras de Gregori Bateson e Charles Sanders Peirce para formular o trabalho de transformação do signo em sentido. A questão do desajuste entre P/R é aqui reenfatizada, uma vez que ela tem efeitos sobre o trabalho analítico do discurso: "é necessário abordar um discurso em relação a sua produção e a sua recepção, pois a análise em produção e em recepção não coincide jamais" (VERÓN, 1991, p.18). E critica a hipótese determinística sobre a produção dos sentidos vista na perspectiva da informação (Emissor/>Receptor): "um discurso não determina apenas um efeito, mas um campo de efeitos" (VERÓN, 1991, p.180). Os efeitos dependem também das distinções das gramáticas, enquanto "regras sobre a produção de um discurso (gramática de produção) e aquelas (gramática de reconhecimento) que visam determinar as condições sobre as quais um discurso é susceptível de produzir efeitos" (VERÓN, 1991, p.180). A descrição abaixo (Fig. 1 e 2) dos diagramas ajuda a compreender a "noção de defasagem entre as instâncias de produção e o reconhecimento" (VERÓN, 1991, p.180).

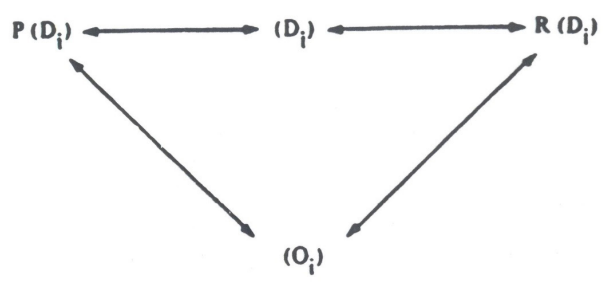

Fig. 1.Modelo de duplas tríades (primeira formalização) Fonte: (VERÓN, 1991, p. 181).

O diagrama 1 (Fig. 1) aponta para a existência de dois níveis, nos quais a produção de sentidos se realiza, mas sem que as tais especificidades tenham sido explicitamente distinguidas ainda como duas tríades. É no diagrama 2 (Fig. 2) que o autor institui as fronteiras e dinâmicas das operações das duas dríades, atribuindo-lhes contornos e fronteiras: 


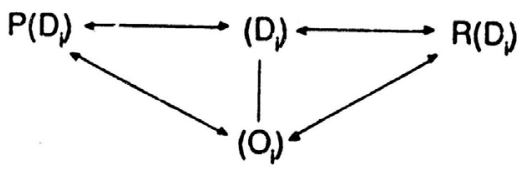

Fig. 2. Modelo de duplas tríades (segunda formalização) Fonte: (VERÓN, 1996, p.132).

Explicando, o autor diz:

Fixando-nos sobre um ponto da rede discursiva, a partir de um discurso de referência (Di), sendo $\mathrm{P}(\mathrm{Di})$ as condições discursivas de produção de (Di), $\mathrm{R}(\mathrm{Di})$ as condições discursivas de reconhecimento de $\mathrm{D}$ (i) e $\mathrm{O}$ (Oi) sendo o objeto do discurso (Di), temos duas relações triádicas, com dois pontos comuns, D (i) e O (i). Para definir o conhecimento, uma epistemologia binária somente reteria a única relação de D (i) com seu objeto; esta epistemologia se constitui pelo desconhecimento da rede interdiscursiva e se alimenta na ilusão do sujeito como fonte do sentido. O modelo de unidade mínima da rede contém duas vezes o gráfico triádico peirceano. Considerado em relação as suas condições discursivas de produção, (Di) é interpretação destas condições, e só nesta medida constitui (Oi) como seu objeto. Considerado em relação com as suas condições produtivas de reconhecimento, em contrapartida, D (i) é signo de seu objeto, e R (Di) torna-se o interpretante na relação triádica. Longe de ser o que corresponde isolado do discurso que o faz falar, o objeto somente existe enquanto tal, dentro e através desta rede interdiscursiva. Considerado na sua ligação com D (i), O (i) pode ser designado como objeto imediato de $\mathrm{D}$ (i), e inserido na relação triádica, $(\mathrm{O})$ é objeto dinâmico (VERÓN, 1991, p.182).

Chama atenção para o processo de circulação que neste modelo vai se complexificando, pois: "se meu objeto 'ultrapassa' o discurso que tenho sobre ele, é porque outros discursos foram e serão sustentados sobre meu objeto" (VERÓN, 1980, p.64). Tanto o discurso quanto o objeto funcionam de modo distinto para cada uma das tríades. Em função das diferenças das gramáticas e de suas lógicas, é impossível pensar o sentido derivando de operações de calculabilidade entre produção/recepção. Tal ênfase é pensada também no funcionamento da comunicação midiática. Para tanto, inspira-se na Fig. 2 para fazer observações manuscritas, em torno de um esboço de diagrama, que aparecem na Fig. 3 e comentadas abaixo: 


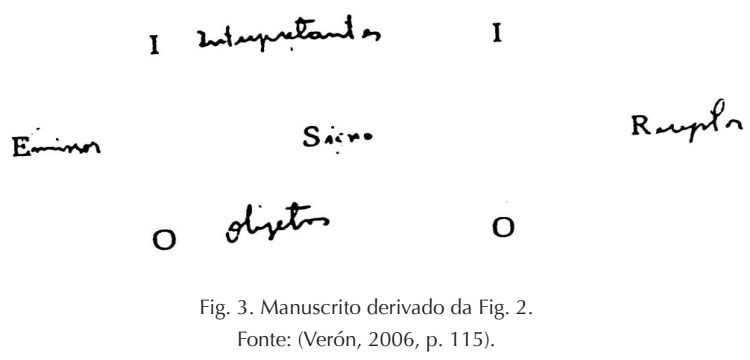

\begin{abstract}
A relação semiótica mínima entre um emissor e um receptor [...] implica, assim, a articulação entre duas tríades, de que a priori, o único elemento comum para um observador é o signo ou representamem (S) na sua manifestação material sensível. A relação \{\} entre os interpretantes (I) e os objetos (O) operando entre $E$ em R, é, para um observador, problemática. Este aspecto problemático decorre da não calculabilidade da circulação e está na origem de todas as dificuldades nos estudos de recepção. [...] A diferenciação entre os dois polos, o da produção e o do reconhecimento, exprime-se na relação problemática entre [...] (I) e (O) no esquema da unidade mínima da produção de sentidos (VERÓN, 2006, p.115-116).
\end{abstract}

Esta elaboração o leva a situar o funcionamento da circulação em uma perspectiva para além de um espaço de trânsito entre E/R, conforme mostram também suas pesquisas sobre práticas discursivas em recepção. Neste contexto, o processo de ativação das gramáticas é fragmentário, uma vez que a palavra individual (como um processo semiótico individualizado) e colhida no trabalho de pesquisa, ultrapassa largamente o discurso midiático em produção. Tal quadro de complexidade potencializa desafios, especialmente quando os equipamentos da observação investigativa falham diante das lógicas da relação social "[que] não se fazem (ou não se fazem mais) lá, onde as procuramos" (VERÓN, 2006, p.124).

$\mathrm{O}$ interesse sobre a recepção já se manifesta em pesquisas sobre as gramáticas em produção dos discursos jornalísticos, algumas feitas no Brasil (FAUSTO NETO, VERÓN e RUBIM, 2003), conforme ele mesmo lembra: “(...) tive a sensação de que longos anos de trabalho sobre o discurso das mídias estavam me dizendo muitas coisas sobre os atores individuais" (VERÓN, 2004b, p.8). Uma ênfase maior se dá nos anos 80, quando retomou de uma forma mais sistemática a problemática de descontinuidades entre gramáticas, questão que torna a "distinção entre o ponto de vista da produção e do reconhecimento [...] sumamente importante" (VERÓN, 1998, p.20). Seus trabalhos empíricos sobre a recepção contemplaram muitos objetos, alguns dos quais publicados na forma de livros, outros não disponibilizados por se constituírem em relatórios institucionais. Eles ensejam a noção de uma semiótica aberta, privilegiando o exame das articulações entre instituições e usuários, algo que dá lugar a investigações mais complexas (VERÓN, 1995a). 
É na observação de "múltiplos mercados discursivos, que circulam na sociedade através dos meios" (VERÓN, 1998, p.95), situação na qual emerge o conceito de contrato de leitura, como "metodologia [...] destinada a identificar e a descrever essas 'maneiras de dizer', que são as que criam o vínculo entre o meio e o leitor" (VERÓN, 1998, p.97). Analisou estratégias midiáticas visando compreender a relação "que une no tempo uma mídia a seus 'consumidores" (VERÓN, 2004a, p.275). Diversas técnicas e o olhar semiótico mobilizado foram além dos marcos conceituais de algumas disciplinas que isolavam a recepção como uma variável dependente. Considerou os anos 80 como marco desafiador para o avanço da pesquisa em recepção:

[... semiótica dos anos 80 integrará em seu marco conceitual uma teoria do reconhecimento, uma teoria dos efeitos de sentido ou não existirá. Ora, sobre o reconhecimento não sabemos quase nada, e a teoria que diz respeito a ele [reconhecimento], em virtude da defasagem necessária entre produção e reconhecimento, não pode ser deduzida de uma teoria da produção discursiva. $\mathrm{Na}$ verdade, enquanto o reconhecimento não for conceitualizado, a teoria da produção permanece incompleta, pois toda produção discursiva é um reconhecimento de outros discursos (VERÓN, 2004, p.83).

Compreendia, desta perspectiva, a semiótica como "uma ciência social: seu objeto é a circulação dos discursos no seio da sociedade [...]; a abordagem semiótica é de natureza intersticial que procura reconstruir a produção de sentido através da redes institucionais; técnicas e discursivas de nossas sociedades" (VERÓN e BOUTAUD, 2007, p.18). Postula o deslocamento da semiótica para a recepção, pois ali "se reencontra diante dos indivíduos, mas dos indivíduos que fazem parte dos leitorados, das audiências, dos públicos" (VERÓN e BOUTAUD, 2007, p.168). Isto implicaria para ele "lidar com a articulação entre a semiose apresentada pelos discursos midiáticos e aquela dos atores individuais que são os consumidores, os intérpretes" (VERÓN e BOUTAUD, 2007, p.168). Em alguns dos relatórios publicados ${ }^{1}$ destacava não só os seus resultados, mas também reflexões sobre o processo metodológico desenvolvido. De um lado lembrava a importância da recuperação da fala dos receptores. Chamava atenção para o fato de que "o sentido dos comportamentos dos usuários de uma biblioteca não pode ser apreendido fora do discurso do próprio usuário, pois o [...] sentido é inteiramente construído pelo usuário e [...] se define segundo seu programa de leitura" (VERÓN, 1998, p.73-74). Autorrefletia sobre a condução metodológica do processo de observação, e neste nível fazia avaliações da sua própria conduta:

[...] [a] elaboração conceitual da $1^{a}$ parte deste estudo, fundada sobre a teoria da enunciação [...] e a segunda parte consagrada a uma primeira exploração das regiões do reconhecimento, [apontam] a necessidade de [...] reduzir pouco

1 As quatro pesquisas realizadas por Verón, no âmbito da semiótica operacional, são: Ethnographie de l'exposition l'espace, le corps et le sens (1989); Les spectacles scientifiques télévisés - figure de la production et de la réception (1985); R.A.T.P. - le métro empire des signes: stratégies pour le cable (1986); Esto no es un libro (1998). 
a pouco a distância entre estas duas problemáticas, [...] nos parece do ponto de vista metodológico, a tarefa mais urgente (FOUQUIER e VERÓN, 1985, p.102).

São essas trajetórias que permitem explicitar que a recepção está situada em complexa articulação ao dizer que o verdadeiro objeto da pesquisa não "é a mensagem em si [...] mas a produção/reconhecimento do sentido, sentido este cuja mensagem não é senão o ponto de passagem" (VERÓN e BOUTAUD, 2007, p.179).

As referências sobre os quatro casos referidos na nota 1 condensam observações sobre as dissenções entre lógicas e postulados da oferta e as da recepção, etc. Lembram que as relações entre instituições e atores chamam atenção de vínculos que são fontes de crescentes complexidades da organização social (VERÓN e BOUTAUD, 2007). $\mathrm{E}$ as manifestações que aparecem nestes processos de articulação/desajuste "são uma prova cabal sobre a não linearidade da comunicação, que resulta do estudo empírico da circulação discursiva" (VERÓN e BOUTAUD, 2007, p.169).

\section{Rumo à semiótica aberta}

Ainda no contexto dos seus ensaios teóricos, examinou a problemática da recepção o cenário da convergência. A partir da rearticulação da atividade comunicacional em torno da convergência de três setores - audiovisual, informática e telecomunicações examinou como os usuários das mídias se inseriram na sua dinâmica. E de um ponto de vista distinto ao da convergência (enquanto perspectiva linear) propôs que o trabalho da recepção se faz segundo sensíveis divergências no âmbito do mercado tecnodiscursivo. Deste ponto de vista, a produção não é a programadora do consumo midiático, passando estas operações às mãos do receptor. Diz ele que "há um fenômeno central que é o deslocamento da programação dos produtores para os usuários [...] isso é a gestão, por parte dos produtores do tempo cotidiano das pessoas. Há muitos pontos sobre esse tema, mas um que me parece interessante [...] é que o tempo social está organizado de maneira diferente" (VERÓN, 2007a, p.41-42). Tal fenômeno vai configurar a importância das lógicas da recepção sobre a organização do consumo midiático, pois a ambiência midiática

[...] transforma-se em uma superfície operatória multimidiática controlada pelo receptor. Haverá sempre, supõe-se, múltiplos produtos áudio visuais (os meios são antes de tudo, um mercado), mas não haverá mais 'programação'. Esta superfície abarcará tudo: informação, entretenimento, computação, telefonia, comunicação interpessoal. (VERÓN, 2007b, p.12)

Diferente de um discurso triunfalista sobre a convergência, aponta de modo críticoanalítico seus efeitos sobre o cenário da midiatização: 
[...] a mediatização de nossas sociedades, ao longo do século XX, não se traduz em fenômenos de homogeneização e de uniformização das relações e práticas sociais, como anunciavam por exemplo, os profetas da Escola de Frankfurt, mostra, pelo contrário, que a interface 'produção-reconhecimento' é precisamente o vínculo de engendramento de uma 'crescente complexidade das sociedades entre produtores e receptores' (VERÓN e BOUTAUD, 2007, p.170).

Para a elaboração do trabalho de observação sobre os cenários da convergência, retoma a questão de suas gramáticas, segundo diagrama formulado em dois momentos (2007 e 2013), nos quais enfatiza a importância do desajuste produção-recepção para explicar o funcionamento da circulação nestes contextos atuais e também apontar sua pertinência para subsidiar estudos sobre a recepção.

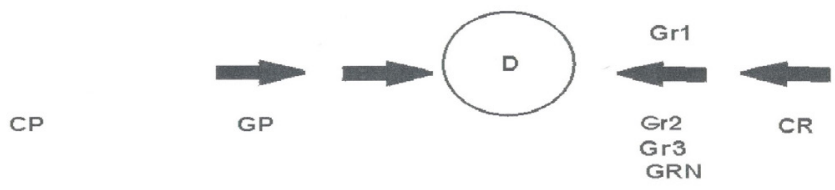

Fig. 4. Esquema da cadeia de circulação de sentidos produção/recepção Fonte: (VERÓN \& BOUTAUD, 2007, p.169).

Na figura acima (Fig. 5), mostra e comenta a complexificação das tríades, a partir das transformações do trabalho das gramáticas (produção e reconhecimento) e das condições de circulação dos discursos, no cenário da sociedade em midiatização:

O que nos interessa aqui é sublinhar o fato de que, se a análise nos permite articular a classe D de discurso a uma gramática de produção dada, as propriedades de $\mathrm{D}$ assim descritas não nos autorizam a inferir os efeitos desta classe de discursos em recepção: a classe D de discurso está submetida, em recepção, a uma pluralidade de leituras, de interpretações que designaremos como gramáticas de reconhecimento $(\mathrm{GR})$ de $\mathrm{D}$, que a seu turno reenviam às condições de reconhecimento (CR) determinadas. Temos aí uma constatação capital sobre a não linearidade da comunicação, que resulta do estudo empírico da circulação discursiva (VERÓN, 2007a, p.169).

A partir do mesmo diagrama, comenta também os efeitos dessas novas dinâmicas sobre a posição do observador no trabalho de pesquisa, neste cenário. Lembra também os efeitos destas questões sobre a problemática metodológica:

Tanto para trás como para frente (para esquerda ou para direita do esquema) encontramos os modelos que o observador deve formular para dar conta 
das problemáticas do DO (Discurso/Objeto). A tarefa do observador é desentranhar (reconstruir) as operações das quais o DO somente mostra traços. Ainda que somente the interesse uma vinculação, dificilmente uma investigação poderá abarcar todos os seus aspectos. Na maioria dos casos, reconstruímos apenas pequenos fragmentos de uma vinculação (VERÓN, 2013, p.205).

Tais efeitos sobre a questão metodológica são sintetizados em três observações: a) a singularidade do modelo, à luz do contexto (da midiatização) atual; b) o reconhecimento de que a questão do desajuste entre $\mathrm{P} / \mathrm{R}$ se torna mais complexo, uma vez que "o esquema da defasagem produção/reconhecimento pressupõe que ambos os polos da circulação estão operando lógicas qualitativamente diferentes [...] que nunca as discuti de maneira direta" (VERÓN, 2013, p.294); e c) interroga o "[...] que são estas lógicas? [...] de onde provêm? [...] por que são diferentes?" (VERÓN, 2013, p.295). Tais interrogações o levam a um novo estágio do seu périplo, talvez o último antes de sua morte.

\section{Retorno à sociologia?}

O olhar sobre estas questões da complexidade comunicacional trazidas desde os estudos dos anos 70 projeta-se em diálogo com a obra de Niklas Luhmann, dela recebendo pistas para liberar a noção de defasagem de sequelas da tradição sociológica. Não se trata de um retorno à sociologia, enquanto disciplina, mas de um outro movimento , através do qual a solução dos problemas colocados supõe um "entrelaçamento de considerações econômicas, sociológicas, culturais, antropológicas e psicossociais. [...] A abordagem semiótica é uma démarche interinstitucional, que busca reconstruir a produção do sentido ao nível das redes institucionais, técnicas e discursivas das nossas sociedades" (VERÓN e BOUTAUD, 2007a, p.18). Comentando a contribuição luhmanniana para a revisão de conceitos, diz que a noção de acoplamentos entre sistema e ambiente requalifica a problemática da descontinuidade entre produção/recepção, uma vez que aclara melhor a noção de defasagem. Pois, esta é uma

\footnotetext{
[...] maneira, no meu entender, negativa de formular o problema, porque talvez seja mais correto pensar que falar de defasagem é falar de ponto de vista do produtor, porque está buscando um acordo, uma articulação por definição, embora seja impossível esta articulação. Então falar de defasagem talvez seja ver o processo do ponto de vista do produtor, pois ele está buscando fasagens, e a sociedade tem defasagens (VERÓN, 2008, p.148).
}

A noção de acoplamento se insere nas discussões sobre os sistemas complexos ao discutir as relações entre ambiente e sistema. Em Luhmann, as articulações se fazem em torno de lógicas distintas, como também assim formula o pensamento e as reflexões do autor argentino sobre produção de sentido (VERÓN, 1978; VERÓN, 2008). 
As convergências entre os conceitos veronianos e luhmannianos se dão através da noção sobre a comunicação afastada do equilíbrio. Se de um lado, temos as descontinuidades nos trabalhos de produção/recepção, mesmo assim tais instâncias se contatam em torno de uma dinâmica de interpenetração, conceito este assim formulado por Luhmann para aludir a uma outra noção interacional entre os polos da comunicação:

O conceito de interpenetração não trata de uma relação geral entre sistema e meio, mas sim de uma relação entre sistemas que pertencem reciprocamente um ao meio do outro. [...] Fala-se em penetração quando um sistema disponibiliza a sua própria complexidade para que outro se construa. [...] existe interpenetração, quando esta situação é recíproca, ou seja, quando ambos os sistemas mutuamente permitem-se proporcionar sua própria complexidade pré-construída. Em caso de penetração, o comportamento do sistema penetrador está codeterminado pelo sistema receptor. No caso da interpenetração, o sistema receptor exerce também uma influência retroativa sobre a formação de estruturas do sistema penetrador, intervindo, portanto, de duas formas: a partir do interior e do exterior. [...] os sistemas que se interpenetram permanecem meio um para o outro, significando que a complexidade que mutuamente disponibilizam é inapreensível, isto é, desordem (LUHMANN, 2009, p. 267-268).

Produção/recepção e sistema/ambiente são realidades auto-organizantes que se contatam através de dinâmicas reciprocizantes, a partir das suas singularidades e configurações. Resulta que, longe de ajustes e convergências, o trabalho de produção de sentido que aí se realiza opera através de complexidades mutuamente disponibilizadas por estas duas instâncias. Longe de qualquer tipo de disponibilização de realidades entre uma e outra dimensão, essas duas (instâncias) exercem dinâmicas retroativas, instaurando instabilidades, descontinuidades; em suma, aspectos longínquos de um cenário de convergência. Aproximando esta formulação do contexto de uma semiótica da comunicação, Verón propõe haver realidades de comunicação nestes dois processos que envolvem sistema e meios (produção/recepção):

[...] não esqueçamos que, para Luhmann (2000 e 1995), os sistemas sociais não são nada de outra coisa que a autopoiesis da comunicação. Os materiais discursivos aos quais o observador accede segundo "pedaços" da semiosis, decompostos na interface produção/reconhecimento, são tomados dentro de dois processos de auto-organização diferentes: aquele do sistema de meios e aquele dos atores (VERÓN e BOUTAUD, 2007a, p.182).

Esta questão, por ele pontuada, indica o surgimento de uma nova ambiência comunicacional - por nós entendida como zonas de contato -, nas quais se manifestam acoplamentos indicando para uma nova organização sociocomunicacional. 


\section{Nota em conclusão}

Não temos a intenção de fazer uma revisão de obra que atravessou muitos anos de estudo. Apenas elegemos alguns aspectos para examinar o modo de trabalho do autor sobre o conceito de recepção. Isso nos leva a concluir, com duas ou três ideias, enquanto intentos interpretativos.

Possível obstáculo dificulta seguir o percurso do autor e se relaciona com o núcleo de conceitos e seu trabalho de elaboração. Se sua pesquisa se faz em décadas, as referências eleitas por ele para estudar recepção se apoiam em matrizes que são reiteradamente mobilizadas em torno de novas formulações. Deste ziguezague resultam hipóteses que ficam como referências para circulação dessas ideias, dentre elas uma alternativa metodológica ao modelo binário para a formulação de uma teoria da produção de sentido, tendo em Peirce uma referência norteadora. Há muitas entradas para leitura desta obra e uma delas que nos parece estimulante é a dinâmica de movimentá-la em torno de novos desenhos de pesquisa. Uma outra entrada se constitui na leitura via diagramas para se compreender pistas deixadas pelo autor sobre sua própria temporalidade em seguir os signos.

Faz em companhia de muitos autores a viagem da epistemologia terciária. Referência esta que justificaria a elaboração de um mapa. As formulações do autor têm vários efeitos de leitura e uma delas se manifesta numa enigmática interrogação, Verón faz pesquisa empírica em comunicação? E sobre recepção? Há inevitavelmente algumas possíveis respostas, mas o seu contrato de leitura frustra o leitor, porque oferece no lugar de respostas novas perguntas. Mas, de alguma forma, o autor responde a estas inquietações oferecendo pistas que podem ser transformadas em novos objetos de estudos. Neste sentido, elege a relação pesquisador/pesquisado como um problema importante no âmbito da epistemologia da terceiridade e como possibilidade desta colaborar para a escuta de palavras individuais, vindas da recepção (VERÓN, 1995). Sugere que o lugar do pesquisador tem nesta interface três níveis de observação: $1^{\circ}, 2^{\circ}$ e $3^{\circ}$ graus. No primeiro, os atores sociais observam. No segundo, os atores midiáticos observam as observações de $1^{\circ}$ grau feitas pelos atores sociais. No terceiro, os observadores do sistema acadêmico observam os atores midiáticos, observando as observações dos atores sociais em $1^{\circ}$ grau. Tais níveis se complexificam ao se entrelaçarem e se interpenetrarem, segundo lógicas de descontinuidades. Estas complexas observações põem por terra o pressuposto da teoria da ação social, segundo o qual "é a partir do ponto de vista do ator e de suas intenções que se deve ter um discurso sobre a totalidade da circulação do sentido [...]" (VERÓN, 2004, p.84). Diante destas transações o autor recomenda aos operadores (principalmente dos sistemas midiático e acadêmico) antes de se perguntarem sobre o que fazer com estas palavras, desenvolverem o ato de compreender o compreender (BATESON, 1972). Ou seja, refletirem sobre os processos que utilizam para descrever e construir mundos. E levarem em conta que os receptores, como observadores de primeiro grau, não estão mais lá onde eles - os operadores de $2^{\circ}$ e $3^{\circ}$ graus - admitem que sempre ali permanecem. 
Antonio Fausto Neto é professor titular da Unisinos; é doutor em Sciences de La Comunication et de L'information na École des Hautes Études en Sciences Sociales (1982). Fez pós-doutorado na UFRJ (1990). É pesquisador 1A do CNPq. Também é professor colaborador do Mestrado Profissional em Jornalismo da UFPB. É presidente do Centro Internacional de Semiótica e Comunicação (CISECO). É autor de livros Mortes em derrapagem, O impeachment da televisão, Ensinando a TV Escola, Desconstruindo os sentidos, Lula Presidente - Televisão e política na campanha eleitoral e $O$ mundo das mídias.

afaustoneto@gmail.com

\section{Referências}

BATESON, G. Steps to an ecology of mind. Nova York: Ballantine, 1972.

BLOOM, H. La angustia de las influencias, una teoría de la poesía. Caracas: Monte Avila, 1977.

FAUSTO NETO, A.; VERÓN, E.; RUBIM, A. C. Lula presidente: televisão e política na campanha eleitoral. São Paulo: Hacker; São Leopoldo, RS: Unisinos, 2003.

LUHMANN, N. Introdução à teoria dos sistemas. Petrópolis: Vozes, 2009.

MELO, A. L. M.; GOBBI, M. C.; HEBERLÊ, A. L. O. (orgs). A diáspora comunicacional que se fez Escola Latino-Americana: as idéias de Eliseo Verón. São Bernardo do Campo: Cátedra Unesco/Metodista; Universidade Metodista de São Paulo, 2008.

REY, G. Eliseo Verón: su obra y su aporte. Signo y Pensamiento, vol. 2, ano 2, n. 3, 1983. p. 17-31

SORGEM. R.A.T.P.: le métro empire des signes: stratégies pour le cable. Paris: Sorgem, 1986.

VERÓN, E. La semiosis social, 2: ideas, momentos, interpretantes. 1. ed. Buenos Aires: Paidós, 2013.

Do contrato de leitura às mutações na comunicação. MELO, A. L. M.; GOBBI, M. C.; HEBERLÊ, A. L. O. (orgs). A diáspora comunicacional que se fez Escola Latino-Americana: as idéias de Eliseo Verón. São Bernardo do Campo: Cátedra Unesco/Metodista; Universidade Metodista de São Paulo, 2008. p. 147-152

Regreso al futuro de la comunicación. Cuadernos de Comunicación, n.3, ano 2007a, Rosario, Argentina. p. 35-42

. La televisión, ese fenómeno "masivo" que conocimos, está condenada a desaparecer. [2007?]. Entrevistadores: Carlos Scolari e Paolo Bertetti. Mediamerica, Torino, [2007b?]. Disponível em: <http:// www.cartmanedizioni.it/libri/mediamerica/>. Acesso em 03 de fev. 2016.

.Os públicos entre produção e recepção: problemas para uma teoria do reconhecimento. In: ABRANTES, José Carlos; DAYAN, Daniel (org). Televisão: das audiências aos públicos. Lisboa: Livros Horizonte, 2006. p. 113-126

.As mídias na recepção: os desafios da complexidade (1991). In: Fragmentos de um tecido. São Leopoldo: Editora Unisinos, 2004a. p.273-284 
Fragmentos de um tecido. São Leopoldo: Editora Unisinos, $2004 \mathrm{~b}$.

Espacios mentales: efectos de agenda 2. Barcelona: Gedisa, 2001.

Esto no es un libro. 1 ed. Barcelona: Editoral Gedisa, 1998.

Semiosis de lo ideológico y del poder: la mediatización. Buenos Aires: UBA, 1997.

. La semiosis social: fragmentos de una teoría de la discursividad. 1 ed. Barcelona: Editorial Gedisa, 1996.

Conducta, estructura y comunicación: escritos teóricos 1959-1973. Buenos Aires: Amorrortu editores, 1995a.

Investigación, semiología y comunicación: del estructuralismo al análisis en producción. Causas y Azares, n.3, 1995b. p. 7-23

. Entre Peirce et Bateson: une certaine idée du sens. In: WINKIN, Y. Bateson: primer inventario de una herencia. Buenos Aires: Paidós, 1991. p. 171-184

La semioses et son monde: langages. Paris: Hachette, 1981.

. A produção de sentido. São Paulo: Cultrix; Editora da Universidade de São Paulo, 1980.

Sémioses de l'idéologie et du pouvoir. Communications, n. 8, 1978a. p. 7-20

Le Hibou. Communications, n. 8, 1978b, Paris. p. 69-126

VERÓN, E.; BOUTAUD, J.J. Sémiotique ouverte: itinéraires sémiotiques en communications. Paris: Lavoisier, 2007.

VERÓN, E. et al. Lenguaje y comunicacion social. Buenos Aires: Ediciones Nueva Visión, 1971.

VERÓN, E.; LEVASSEUR, M. Ethnographie de l'exposition: I'espace, le corps et le sens. Paris: Centre Georges Pompidou, 1989.

VERÓN, E.; FOUQUIER, E. Les spectacles scientifiques télévisés: figures de la production et de la réception. Paris: La Documentation française, 1985.

VERÓN, E.; SLUZKI, C. Comunicación y Neurosis. Buenos Aires: Instituto Torcuato di Tella, 1970.

Artigo recebido em abril e aprovado em junho de 2016. 